\title{
Transvers kolonda nadir görülen bir vasküler malformasyon (kavernöz hemanfiom)
}

\section{A rare vascular malformation in the transverse colon (cavernous hemangioma)}

\author{
(D) Firdevs TOPAL ${ }^{1}$, (D) Sabiye AKBULUT ${ }^{2}$, (D) Ünal TAŞDEMIR ${ }^{1}$, (D) Cengiz KARAHANLI' ${ }^{1}$, (D) Elif SARITAŞ YÜKSEL ${ }^{1}$, \\ (D) Fatih Esad TOPAL ${ }^{3}$ \\ Izmir Katip Çelebi Üniversitesi, Atatürk Eğitim ve Araştırma Hastanesi, ${ }^{1}$ Gastroenteroloji Bilim Dall, ${ }^{3}$ Acil Tip Bilim Dah, Izmir \\ ${ }^{2}$ Sağllk Bilimleri Üniversitesi, Kartal Koşuyolu Yüksek Ihtisas Sağlık Uygulama ve Araștırma Merkezi, Gastroenteroloji Bilim Dall, Istanbul
}

Gastrointestinal sistemde venöz malformasyonlar (önceden kavernöz hemanjiom olarak bilinirdi) nadir olarak görülen vasküler malformasyonlardır. Rektal kanama en sık görülen semptomdur, obstrüksiyon bulgularnna bağlı yakınmalar ise oldukça nadirdir. Özellikle rektal ve sigmoid bölgede lokalize olanlarda kanama daha sık olarak görülmektedir. Biz burada acil servise şiddetli karın ağrısı yakınması ile gelen, rektal kanama ve ekstraintestinal bulguların eşlik etmediği, ancak tanısal tetkikler sonucunda transvers kolonda kavernöz hemanjiom tanısı konulan bir olguyu sunmaktayı.

Anahtar kelimeler: Venöz malformasyon, kavernöz hemanjiom, kolon, kolonoskopi, cerrahi

\section{GIIRIS}

Hemanjiyomlar genel olarak baş ve boyun bölgesinde sık olarak görülen benign tümörlerdir. Gastrointestinal traktın herhangi bir bölgesini tutabilirler, fakat klinik pratikte kolonik hemanjiomlar oldukça nadirdir (1). Kolonda en sık görüldüğü yer ise rektosigmoid bölgedir (2). Kavernöz hemanjiyomlarına; sıklıkla kanama (\%60-90), anemi (\%43), obstrüksiyon (\%17) ve nadiren trombosit sekestrasyonu eşlik eder $(1,2)$. Klinik prezentasyonu genellikle akut, rekürren veya kronik rektal kanama şeklindedir (3). Biz burada acil servise şiddetli karın ağrısı yakınması ile başvuran; rektal kanama bulgusu olmayan, transvers kolonda kavernöz hemanjiyom tanısı alan bir olguyu sunmaktayı.

\section{OLGU SUNUMU}

Yirmi üç yaşında, kadın hasta, şiddetli karın ağrısı yakınması ile acil servisimize başvurdu. 3 yıldır aralıklı olan karın ağrısı yakınmasının olduğunu, fakat son bir ayda şiddetinin giderek arttığını belirtti. Hastanın özgeçmişinde ve soy geçmişinde özellik yoktu. Fizik muayenesinde vital bulguları stabildi. Fizik muayenede epigastrik bölgede palpasyonda hafif bir hassasiyeti mevcuttu. Laboratuvar bulgularl; rutin biyokimya parametreleri, hemogram, inflamatuvar ve hemostaz parametreleri normal sinırlardaydı. Abdominal bilgisayarlı tomografi (BT) çekildi; tomografide transvers kolonun distal kısmında diffüz duvar kalınlaşması, mukozal kalınlaşma ve kontrastlanma artışı ile birlikte duvar içinde flebolitlere ait milimetrik kalsifikasyon odakları (uzun ok) ve anterior peri-
Venous malformations (previously known as cavernous hemangioma) in the gastrointestinal tract are rare vascular malformations. Rectal bleeding is the most common symptom; complaints due to obstruction are very rare. Bleeding is common, especially when the venous malformations are localized in the rectal and sigmoid regions. Patients with this condition usually visit the emergency room with complaints of severe abdominal pain and rectal bleeding and without any extraintestinal findings. However, we present a case that was diagnosed as cavernous hemangioma in the transverse colon as a result of diagnostic investigations.

Keywords: Venous malformation, cavernous hemangioma, colon, colonoscopy, surgery

kolonik yağ dokusu içerisinde genişlemiş drenaj venleri (kısa oklar) izlenmekte idi (Resim 1).

Tüm bu işlemler için hastaya bilgilendirilmiş gönüllü olur/ onam formu imzalatıldı. Hastaya kolonoskopi planlandi. Yapilan kolonoskopide; transvers kolon distalinde yer yer polipoid görünümlü, sinırları düzensiz, mor renkli submukozal lezyonlar izlendi (Resim 2). Kavernöz hemanjiyom tanısı ile opere edildi. Ameliyat sirasinda transvers kolonda lokalize lezyon görüldü (Resim 3). Segmental transvers kolon rezeksiyonu uygulanarak, uç-uca kolon anastomozu yapılıp ameliyat sonlandırıldı. Ameliyat materyalinin patolojik değerlendirmesi tipik kavernöz hemanjiyom (submukozadaki bağ dokusu ile desteklenen, kanla dolu sinüs benzeri boşluklardan oluşan kavernöz hemanjiyom) olarak raporlandı (Resim 4). Ameliyat sonrası komplikasyon gelişmeyen ve ağrı yakınması gerileyen hasta taburcu edildi.

\section{TARTISSMA}

Gastrointestinal hemanjiyomlar; nadir olarak görülen, benign vasküler neoplazmlardır (4). Insidansı \%0.06-0.3 arasında değişmektedir (5). Konjenital sendromların (Osler-Weber-Rendu hastalığı, Maffucci sendromu, Klippel-Trénaunay sendromu ve Mavi Nevüs sendromu gibi) bir bileşeni olarak; ekstraintestinal lokalizasyonlarda da tutulum eşlik edebilir (6). En sık görülen semptom; aralıklı ve ağrısız rektal kanamalardır, anemi, trombositopeni ve tüketim koagülopatisi de eşlik edebilir $(1,2)$. 


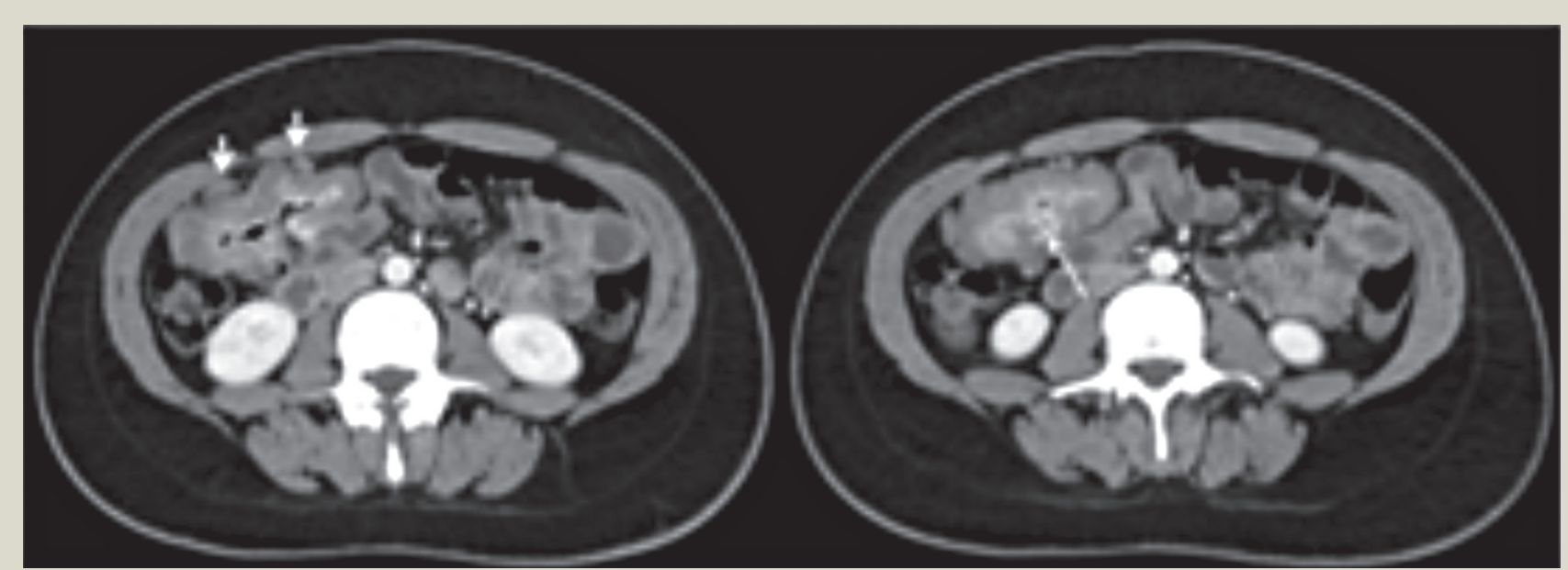

Resim 1. Aksiyel abdominal BT kesitleri.
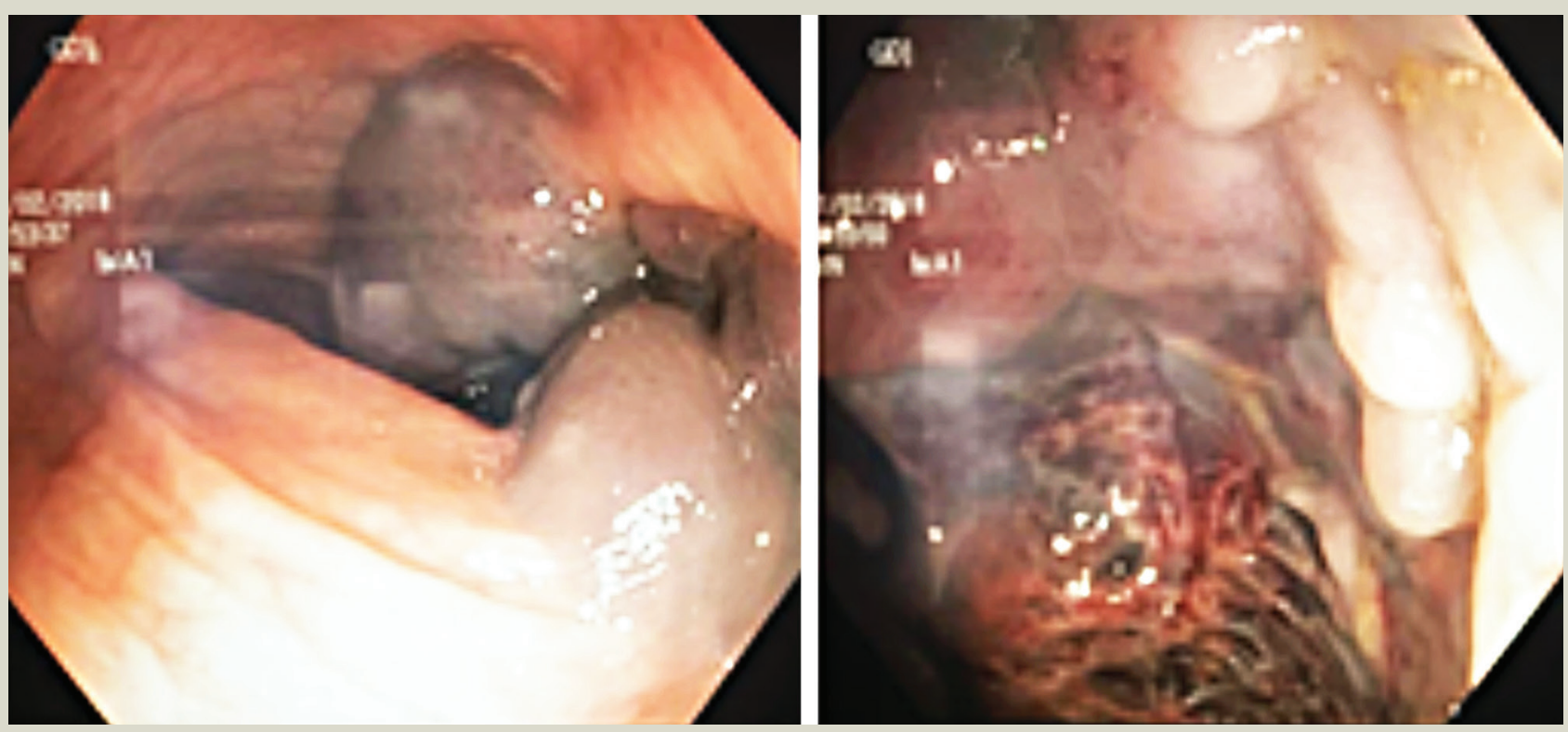

Resim 2. Transvers kolonda mor renkli damar genişlemesi.

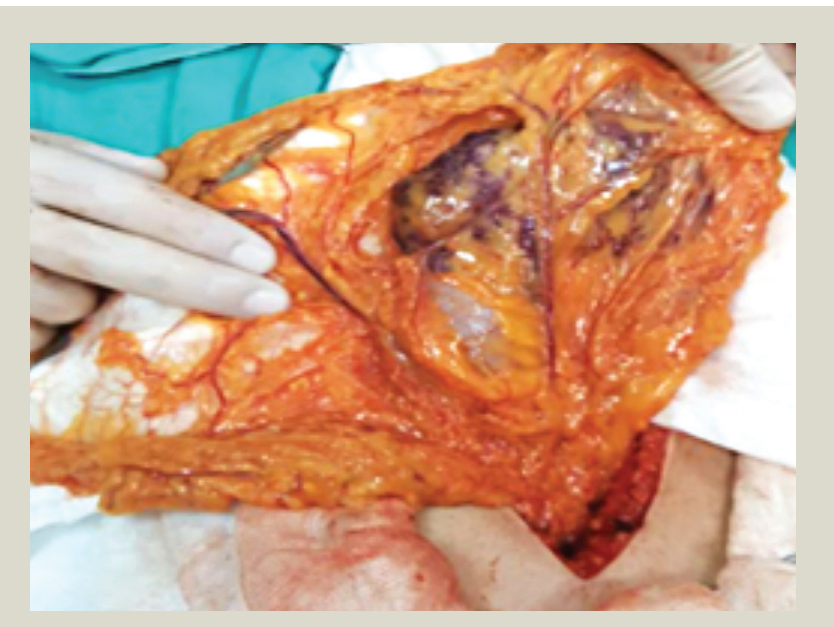

Resim 3. Rezeke kolonda kavernöz hemanjiom.
Gastrointestinal hemanjiyomlar genellikle ince barsak ve midede lokalizedir, kolonda nadir olarak bulunurlar. Kolonda en sık olarak rektum ve sigmoid kolonda lokalize olurlar (7). 1939 ylında ilk kez Philips tarafindan rektal hemanjiyom vakası rapor edilmiştir (8). Kolonik hemanjiyomlar; submukozal vasküler pleksustan orijin alan benign lezyonlardır, embriyo periyodu esnasinda mezoderm dokunun anormal gelişmesine bağlı olarak geliştikleri bilinmektedir $(7,9)$.

Dünya Sağllk Örgütü hemanjiyomların subtiplerini; kapiller, kavernöz, arterivenöz, venöz, intramüsküler, syno-vial olarak sınıflandırmıştır. Genellikle kavernöz ve kapiller olmak üzere iki tipi yaygındır. Kolonik hemanjiyomların yaklaşı olarak \%80'i kavernöz, \%10'dan daha azı ise kapiller hemanjiomlardır $(7,9)$. 


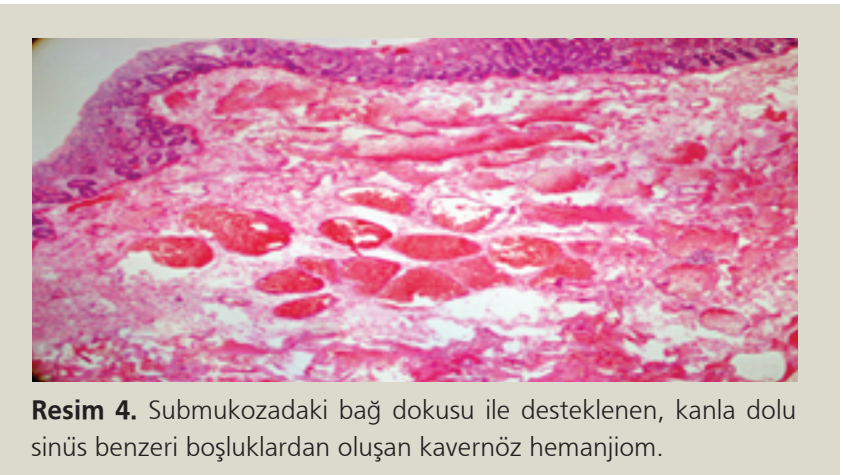

Tanıda; kolonoskopi, BT, magnetik rezonans görüntüleme (MRG) yer almaktadır. Kolonoskopi tanı ve ayırıcı tanı açısından önemlidir; lezyonun lokalizasyonu, uzunluğu tanımlanır. Kolonoskopide tipik bulgular; kolon duvarında mukozadan kabarık, mavi dilate damarlar, mavi nodüler lezyonlar ile karakteristiktir. Biyopsi bazı olgularda gerekli olabilirse de kanama riski nedeniyle genellikle yapilmaz. Abdominal radyografiler hastaların \%25-50'sinde patognomik olan fleboliti gösterir (8). Tanının desteklenmesi, tutulum yaygınlığının belirlenmesi ve operasyon planının çizilmesi açısından BT veya MRG önemlidir (4). Ayırıcı tanıda; adenomatöz polip, karsinom, hemoroid, inflamatuvar barsak hastalığı ve diğer vasküler malformasyonlar (arteriyovenöz malformasyon, anjiodisplazi) yer alır. Tedavi; lezyonun tamamının cerrahi olarak rezeksiyonudur, endoskopik olarak da; lezyonun boyutu, durumuna göre mukozal rezeksiyon, endoskopik submukozal diseksiyon (1) ve palyatif yöntemler (skleroterapi, kriyocerrahi ve lezyonun anjiyografik yolla embolizasyonu) kullanılabilir (6).

\section{"Tüm yazarlar herhangi bir çıkar çatışması olmadığını kabul ederler."}

\section{KAYNAKLAR}

1. Ogasawara N, Suzuki M, Adachi K, Yamaguchi Y, Yamamoto S, Hijikata Y, Ebi M, Funaki Y, Sasaki M, Kasugai K. Endoscopic Resection of a Pedunculated Cavernous Hemangioma of the Sigmoid Colon: A Case Report. Case Rep Gastroenterol. 2019 Oct 1;13(3):418-422.

2. Hsu RM, Horton KM, Fishman EK. Diffuse cavernous hemangiomatosis the colon: findings on three-dimensional CT colonography. Am J Roentgenol 2002;179:1042-4.

3. Vilallonga R, Espin Basany E, Armengol M. Cavernous hemangioma: unusual benign tumor of the transverse colon. Turk J Gastroenterol. 2009 Jun;20(2):146-9.

4. Cotzias E, Rehman SF, Arsalani Zadeh R, Smith D. Conservative management of diffuse cavernous haemangioma of the sigmoid and rectum. Ann R Coll Surg Engl. 2020 Jan;102(1):el-e3.

5. Gentry RW, Dockerty MB, Clagett OT. Vascular malformations and vascular tumors of the gastrointestinal tract. Surg Gynecol Obstet. 1949;88:281-323.

6. Mirioglu S, Cavus B, Iliaz R, Besisik F. Diffuse Cavernous Hemangioma of the Colon. Acta Gastroenterol Belg. 2016 Jul-Sep;79(3):393-394.

7. Levy AD, Abbott RM, Rohrmann CA Jr, Frazier AA, Kende A. Gastrointestinal hemangiomas: imaging findings with pathologic correlation in pediatric and adult patients. AJR Am J Roentgenol. 2001 Nov;177(5):1073-81.

8. Zeng Z, Wu X, Chen J, Luo S, Hou Y, Kang L. Safety and Feasibility of Transanal Endoscopic Surgery for Diffuse Cavernous Hemangioma of the Rectum. Gastroenterol Res Pract. 2019 Jun 19; 2019.

9. Lyon DT, Mantia AG. Large-bowel hemangiomas. Dis Colon Rectum. 1984 Jun;27(6):404-14. 